This item was submitted to Loughborough's Research Repository by the author.

Items in Figshare are protected by copyright, with all rights reserved, unless otherwise indicated.

The custom-made titanium orbital floor prosthesis in reconstruction for orbital floor fractures

PLEASE CITE THE PUBLISHED VERSION

http://dx.doi.org/10.1016/S0266435602002498

PUBLISHER

(C) Elsevier

VERSION

AM (Accepted Manuscript)

LICENCE

CC BY-NC-ND 4.0

REPOSITORY RECORD

Hughes, C.W., K. Page, Richard J. Bibb, J. Taylor, and P. Revington. 2019. "The Custom-made Titanium Orbital Floor Prosthesis in Reconstruction for Orbital Floor Fractures". figshare.

https://hdl.handle.net/2134/14452. 
This item was submitted to Loughborough's Institutional Repository (https://dspace.lboro.ac.uk/) by the author and is made available under the following Creative Commons Licence conditions.

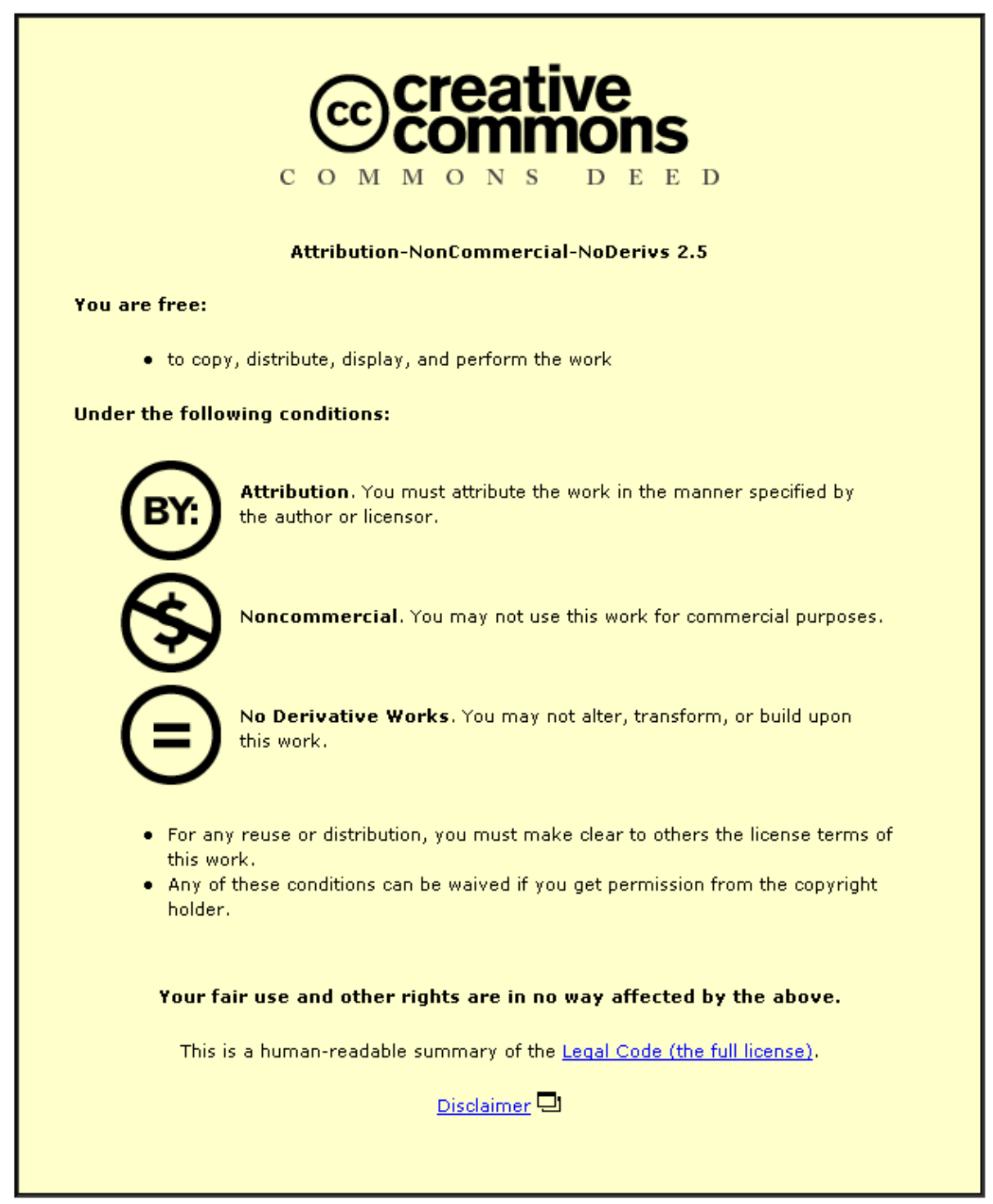

For the full text of this licence, please go to: http://creativecommons.org/licenses/by-nc-nd/2.5/ 


\title{
The custom-made titanium orbital floor prosthesis in reconstruction for orbital floor fractures.
}

\author{
AUTHORS \\ C. W. Hughes FDSRCS, FRCS (Specialist Registrar) ${ }^{1}$ \\ K. Page FIMPT (Chief Maxillofacial Technician) ${ }^{1}$ \\ R. Bibb PhD (Research Fellow Medical Applications) ${ }^{2}$ \\ J. Taylor (Superintendent CT Radiographer) ${ }^{1}$ \\ P. Revington TD, FDSRCS, FRCS (Consultant) ${ }^{1}$ \\ 1. Frenchay Hospital, Bristol, BS16 1LE, UK \\ 2. The National Centre for Product Design \& Development Research, Cardiff, CF5 2YB, UK
}

\section{INTRODUCTION}

Few anatomical sites of such diminutive size have attracted so much variation in treatment as the orbital floor and its related fractures. The range of implant material in reconstruction following blow out fracture of the orbit is extensive and the decision as to which material is used remains debated ${ }^{1}$.

Autologous materials offer clear advantages with cartilage, calvarial bone, antral bone, rib and ilium described ${ }^{1}$. These grafts offer uncertain longevity and carry with them donor site morbidity. Alloplastic materials such as Silastic carry the largest track record but in addition, a well-documented complication rate related in particular to extrusion of the graft ${ }^{2}$. Other alloplastic materials such as polyethylene sheeting (Medpore) are reported as having satisfactory results ${ }^{3}$ and newer resorbable materials such as polydioxanone offer an alternative ${ }^{4}$. The role of bioactive glass is more recently reported but its use is limited by defect size ${ }^{5}$. Titanium for some time in other sites has offered an inert material of proven track record ${ }^{6.7}$ but in its pre-formed presentation can be cumbersome for use in the orbital floor and if removal is required can present an operative challenge.

Continued development in CAD/ CAM technology with stereolithographic model construction offers unparalleled reproduction of anatomical detail ${ }^{89} 10$. The use of this technology is described in relation to planning in trauma surgery ${ }^{9}$ and in planning for ablative surgery for head and neck malignancy

12.13. Custom fit orbital floor implant construction is possible ${ }^{14.15}$, although the material of choice is debated.

We describe a simple technique for construction of custom-made titanium orbital floor implants using easily available laboratory techniques combined with stereolithographically produced models. We estimate the cost of construction of an implant at around $£ 300$. This is largely accounted for by the cost of producing the model which, depending on the height of orbital contour required on the model, varies between $£ 200$ and $£ 300$. The making of the implant takes about 2 hours of a maxillofacial technician's time and the medical-grade titanium sheet costs only a few pounds. This compares favourably with some of the newer alloplastic materials. This cost would drop substantially with greater use of the technique, and when reduced operating time is taken into account, the comparison is more favourable.

\section{TECHNIQUE}

\section{Imaging}

Scanning protocols are observed to minimise ionising radiation dosage to orbital tissues ${ }^{16}$. Maximum detail can be obtained scanning with a $0.5 \mathrm{~mm}$ collimation, but the $77 \%$ increase in dosage when 
compared to using a $1 \mathrm{~mm}$ collimation may not be justified. We use a Siemens Somatom Plus 4 Volume Zoom scanner and scan using parameters: $140 \mathrm{kV}, 120 \mathrm{MAS}, 1 \mathrm{~mm}$ collimation, 3.5 feed per rotation, 0.75 rotation time giving a displayed CTDiW of $45 \mathrm{mGY} / 100 \mathrm{MAS}$. Data are reconstructed using $1 \mathrm{~mm}$ slice width with $0.5 \mathrm{~mm}$ increment ( $50 \%$ overlap) and very smooth kernel. Sharp reconstruction kernels normally associated with CT imaging of bony anatomy introduce an artificial edge enhancement. If used as part of a 3D volume based on selection of specific Houndsfield values; the enhancement artefact will be included with the bony detail therefore degrading the image. The data obtained can be used to construct very sharp multi planer reformats for bony detail and 3D imaging for both hard copy imaging and for stereo viewing by the surgeons.

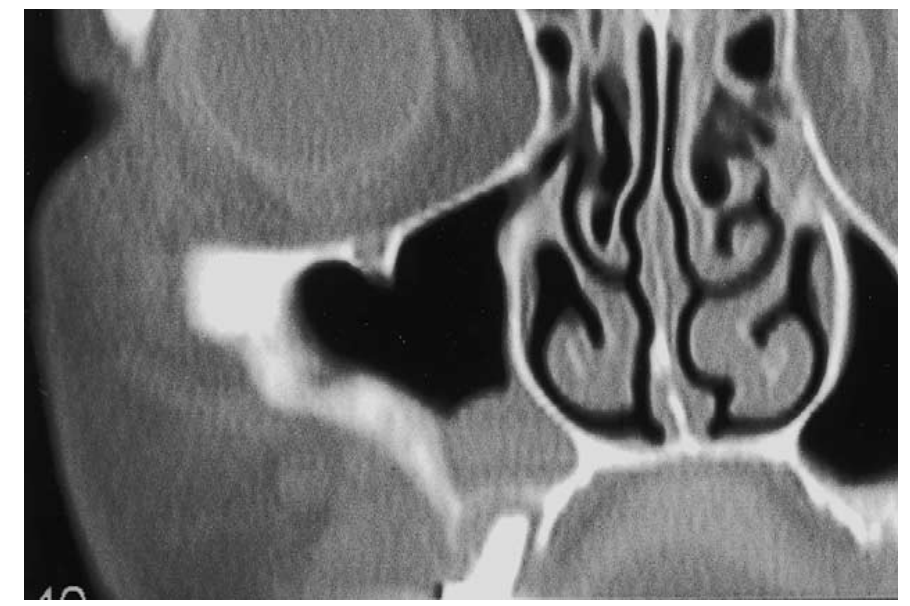

FIGURE 1: Coronal CT scan demonstrating classical orbital blowout fracture.

\section{Model Construction and Stereolithography Apparatus (SLA) Overview}

The CT data are segmented to select the desired tissue type, usually compact bone. Region growing algorithms are then used to select the particular part of the anatomy required. The data is interpolated to increase resolution both in the scan plane and between the scan planes. Interpolation between the scan planes is done using a cubic algorithm that produces an accurate and natural appearance. The SLA machine creates models from a liquid resin that cures to solid when exposed to ultra violet light. An ultra violet laser scans the area of each slice to produce a solid layer. The model build platform is lowered by one layer thickness and more resin floods over the solidified layer. A recoating blade levels the resin and the next layer is scanned on top of the first, and so on until the model is complete.

When this process is being used for reconstruction of the orbital floor, scans are typically taken in the axial plane at intervals exceeding $1 \mathrm{~mm}$. This means that very thin bone that lies predominantly axially may fall between consecutive scans and therefore not be present in the data or 3D model created from it. To overcome this however, scans are taken using a smooth kernel at a slice distance of $1 \mathrm{~mm}$ but with a $0.5-\mathrm{mm}$ overlap as described above. This improves the resolution of the data in these thin areas. The detail created is exceptionally good. To maintain the greatest level of accuracy an epoxy resin was chosen (SL5220). This type of resin shows almost no shrinkage during the photopolymerisation process and therefore can produce models with excellent accuracy. 


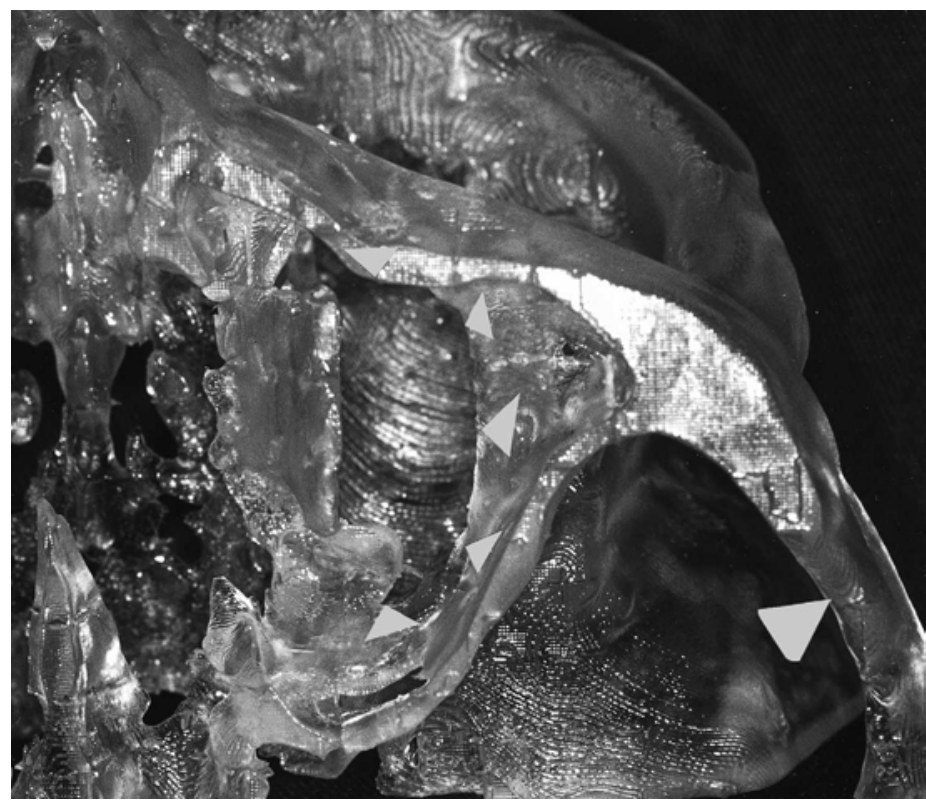

FIGURE 2: Stereolithographic model constructed from epoxy resin demonstrates the "trap door" defect in the left orbital floor when viewed from below as if sitting in the maxillary antrum looking up (margins arrowed).

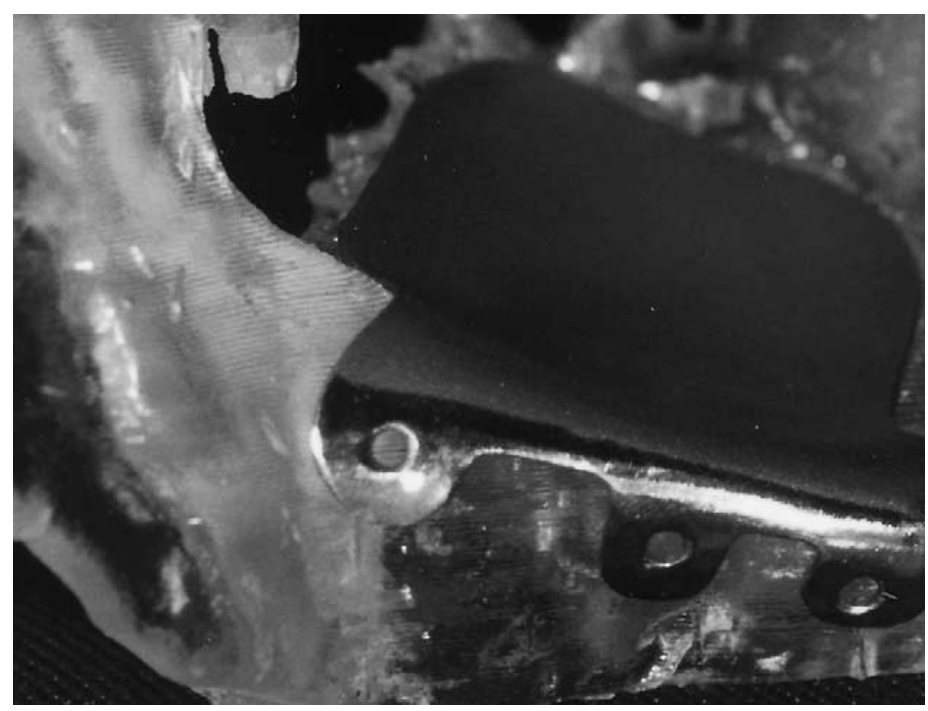

FIGURE 3: The custom titanium implant is seen on the master model.

\section{Construction of the prosthesis}

From stereolithographically produced 3D models, the orbital defect is easily seen and assessed. The orbital defect is then filled using wax to reproduce a like contour to the contralateral side and an impression is taken of both orbital cavities using silicon putty impression material. The orbital injury side is then reproduced by pouring a hard plaster/stone model. The defect has been filled and therefore appears in its proposed reconstructed form. Using pressure flasks usually used in denture construction a layer of $0.5 \mathrm{~mm}$ medical grade titanium is then swaged onto the stone/plaster model of the orbital floor producing an exact replica of the proposed orbital floor and rim contour. The titanium sheet may then be trimmed to allow sufficient overlap and the positioning of a flange for screw fixation. The prosthesis is polished and may be sterilised for use according to local protocol for titanium implants. 


\section{CASE REPORT}

A54-year-old man sustained a blow-out fracture of the left orbital floor and presented with diplopia and restriction of upward gaze. Coronal plane CT showed the fracture (Fig. 1). A stereolithographic model was constructed, which shows the trap door of the fractured orbital floor well (Fig. 2). The model was then used to construct a plaster cast of the orbital defect. A medical-grade titanium prosthesis was constructed from this working cast (Fig. 3). The prosthesis was packaged and sterilised by the hospital central sterile supplies department according to the standard protocol for titanium medical implants. The approach to the orbital floor was by a subciliary incision and the defect was exposed. Herniation and entrapment of periglobar fat was released and the defect prepared in a standard way. The prosthesis fitted perfectly and was stabilised with $1.3 \mathrm{~mm}$ titanium screws from a standard plating kit (Fig. 4). Forced duction was confirmed as normal. Postoperative recovery was uneventful and radiographs revealed the prosthesis to be correctly positioned (Fig. 5a and b). At follow up complete return to normal range of ocular movement was found with resolution of the diplopia and no evidence of complications.

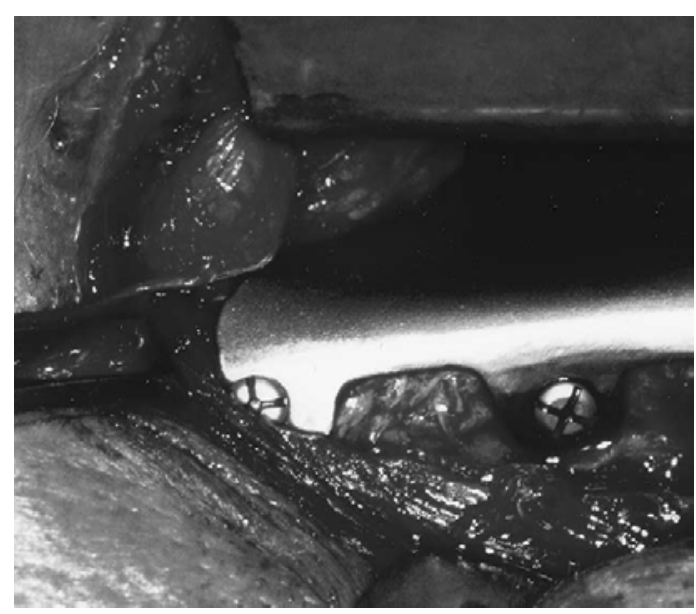

FIGURE 4: The implant inserted and fixed with $1.3 \mathrm{~mm}$ screws. The very precise fit is seen.

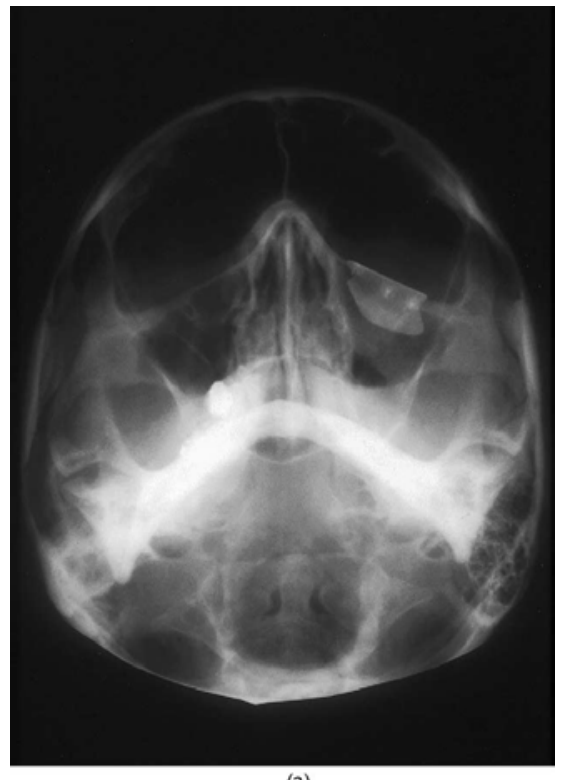

(a)

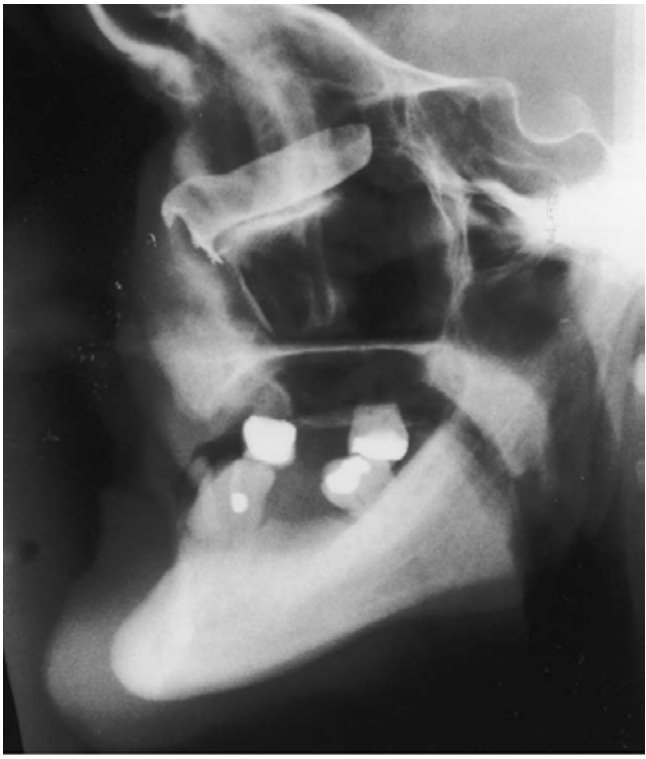

(b)

FIGURE 5 (a) and (b): Plain radiographs in the anterior-posterior and lateral planes showing the position of the implant postoperatively. 


\section{CONCLUSION}

We think that this technique has much to offer both in its simplicity and in the reliability of titanium as a prosthetic material. The laboratory techniques are simple and readily available in most maxillofacial laboratories. The models require off-site production but their use is felt especially valid in cases where defects may be complicated in three-dimensions and where operating time should be reduced to a minimum. The cost of construction of models will reduce significantly if numbers increase, meaning the technique may offer a financially viable alternative to current orbital floor prostheses.

\section{ACKOWLEDGEMENTS}

No financial support was given. The National Centre for Product Design \& Development Research (PDR) kindly supplied the stereolithographic models used in fabrication of the prostheses.

\section{REFERENCES}

1. Courtney DJ, Thomas S, Whitfield PH. Isolated orbital blow out fractures: survey and review. Br J Oral Maxillofac Surg 2000: 38: 496-503

2. Morriston AD, Sanderson R, Moos KF. The use of silastic as an orbital implant for reconstruction of orbital wall defects: Review of 311 cases treated over 20 years. J Oral Maxillofac Surg 1995: 53: 412-417

3. Rubin PAD, Bilyk JR, Shore JW. Orbital reconstruction using porous polyethylene sheets. Opthalmology 1994: 101: 1697-1708

4. Iizuka T, Mikkonen P, Paukku, Lindqvist. Reconstruction of orbital floor with polydioxanone plate. Int J Oral Maxillofac Surg 1991: 20: 83-87

5. Kinnunen I, Aitasalo K, Pollonen M, Varpula. Reconstruction of orbital floor fractures using bioactive glass. J Craniomaxillofac Surg 2000: 4: 229-34

6. Park HS, Kim YK, Yoon CH. Various applications of titanium mesh screen implant to orbital wall fractures. J Craniofac Surg 2001: 6: 555-60

7. Dietz A, Ziegler CM, Dacho A, Althof F, Conradt C, Kolling G, von Boehmer H, Steffen H. Effectiveness of a new perforated $0.15 \mathrm{~mm}$ poly-p-dioxanon-foil versus titanium dynamicmesh in reconstruction of the orbital floor. J Craniomaxillofac Surg 2001: 2: 82-88

8. Bouyssie JF, Bouyssie S, Sharrock P, Duran D. Stereolithographic models derived from x-ray computed tomography. Reproduction accuracy. Surg Radiol Anat 1997: 3: 193-199

9. Bibb R, Brown R. The Application of Computer Aided Product Development Techniques in Medical Modelling. Biomed Sci Instrum 2000: 36: 319-324

10. Kermer C, Lindner A, Friede I, Wagner A, Millesi W. Preoperative stereolithographic model planning for primary reconstruction in craniomaxillofacial trauma surgery. J Craniomaxillofac Surg 1998: 3: 136-9

11. D’Urso PS, Barker TM, Earwaker WJ, Bruce LJ, Atkinson RL, Lanigan MW, Arvier JF, Effeney DJ. Stereolithographic biomodelling in cranio-maxillofacial surgery: a prospective trial. J Craniomaxillofac Surg. 1999: 1: 30-7

12. Kermer C, Rasse M, Lagogiannis G Undt G, Wagner A, Millesi W. Colour stereolithography for planning complex maxillofacial tumour surgery. J Craniomaxillofac Surg 1998: 6: 360-2

13. Hoffmann J, Cornelius CP Groten M, Probster L, Pfannenberg C Schwenzer N. Orbital reconstruction with individually copy-milled ceramic implants. Plast Reconstr Surg 1998: 3: 604-612 
14. Holk DE, Boyd EM Jr, Ng J, Mauffray RO. Benefits of stereolithography in orbital reconstruction. Opthalmology 1999: 6: 1214-8

15. Ionising Radiation (medical exposure) Regulations; 2000: Department of Health Publication. 